\title{
Surveillance for European bat lyssavirus in Swiss bats
}

\author{
A. Megali • G. Yannic $\cdot$ M.-L. Zahno \\ D. Brügger $\cdot$ G. Bertoni $\cdot$ P. Christe $\cdot$ \\ R. Zanoni
}

Received: 8 May 2010/Accepted: 2 July 2010/Published online: 28 August 2010

(C) Springer-Verlag 2010

\begin{abstract}
Most countries in Western Europe are currently free of rabies in terrestrial mammals. Nevertheless, rabies remains a residual risk to public health due to the natural circulation of bat-specific viruses, such as European bat lyssaviruses (EBLVs). European bat lyssavirus types 1 and 2 (EBLV-1 and EBLV-2) are widely distributed throughout Europe, but little is known of their true prevalence and epidemiology. We report that only three out of 837 brains taken from bats submitted to the Swiss Rabies Centre between 1976 and 2009 were found by immunofluorescence (FAT) to be positive for EBLVs. All three positive cases were in Myotis daubentoni, from 1992, 1993 and 2002. In addition to this passive surveillance, we undertook a targeted survey in 2009, aimed at detecting lyssaviruses in live bats in Switzerland. A total of 237 bats of the species M. daubentoni, Myotis myotis, Eptesicus serotinus
\end{abstract}

G. Yannic, P. Christe and R. Zanoni share senior authorship of this article

A. Megali · G. Yannic · P. Christe

Department of Ecology and Evolution, University of Lausanne,

Le Biophore, 1015 Lausanne, Switzerland

G. Yannic

Centre de coordination ouest pour l'étude et la protection des chauves-souris, Suisse, 1 Rte de Malagnou, 1208 Geneva, Switzerland

M.-L. Zahno · D. Brügger · G. Bertoni · R. Zanoni Swiss Rabies Centre, Institute of Veterinary Virology, Länggass-Strasse 122, 3012 Bern, Switzerland

G. Yannic ( $\square)$

Département de biologie and Centre d'études nordiques, Université Laval, 1045 avenue de la Médecine, Québec, QC G1V 0A6, Canada

e-mail: glenn.yannic@gmail.com and Nyctalus noctula were captured at different sites in western Switzerland. Oropharyngeal swabs and blood from each individual were analysed by RT-PCR and rapid fluorescent focus inhibition test (RFFIT), respectively. RNA corresponding to EBLV-2 was detected from oropharyngeal swabs of a single $M$. daubentoni bat, but no infectious virus was found. Molecular phylogenetic analysis revealed that the corresponding sequence was closely related to the other EBLV-2 sequences identified in previous rabies isolates from Swiss bats (particularly to that found at Geneva in 2002). Three M. daubentoni bats were found to be seropositive by RFFIT. In conclusion, even though the prevalence is low in Switzerland, continuous management and surveillance are required to assess the potential risk to public health.

\section{Introduction}

Bats across the world have been recognized as reservoir hosts for a number of emerging infectious diseases and zoonoses that can cross the species barriers and infect other mammals, including humans (reviewed in [1, 2]). Rabies is the oldest recorded zoonosis, and still the most important one using bats as a reservoir host [3].

Rabies is a worldwide viral zoonosis that can infect all mammals, including humans (for a recent review, see ref. [4]). The infection is due to lyssaviruses (genus Lyssavirus, family Rhabdoviridae), and several species of carnivore, apart from bats, act as reservoirs. There are currently 11 recognized species [5-7] and one newly described genotype in the genus Lyssavirus [8], including the European bat lyssavirus type 1 (EBLV-1, genotype 5) and the European bat lyssavirus type 2 (EBLV-2; genotype 6). All but one genotype (Mokola virus) have been found in bats 
[9]. The first rabid insectivorous bat in Europe was recorded in Hamburg, Germany, in 1954 [10]. Over 850 cases of rabies-positive bats have subsequently been recorded between 1977 and 2008 [11]. Most of the cases were EBLV-1, and 95\% of all reported EBLV-1 infections were found in serotine bats, Eptesicus serotinus [12, 13]. By contrast, EBLV-2 has been discovered only 20 times to date, mostly in Daubenton's bats, Myotis daubentoni, in Finland [14], Switzerland [15], the United Kingdom [16, 17] and Germany [18] and in pond bats, Myotis dasycneme, in the Netherlands [12]. So far, the Netherlands and Germany are the only countries where both genotypes have been isolated from rabies-positive bats $[12,18]$.

EBLVs are of public health concern, as both EBLV-1 and EBLV-2 have been transmitted to humans and resulted in fatalities (for a recent review, see ref. [4]). In 1985, a bat researcher in Finland died of rabies encephalitis caused by EBLV-2b [19]. However, the geographical location of the infection could not be pinpointed because this researcher had handled bats in several countries, including Switzerland, during the previous years. In a targeted surveillance, undertaken in 1986 in southern Finland, no lyssavirus infection could be detected from a sample of 183 bats [20]. The first EBLV-2-positive Daubenton's bat in Finland was finally reported in 2009 [14]. Phylogenetic analysis showed that the EBLV-2b isolate from the human case in 1985 was most closely related to the recent Finnish bat isolate, indicating that the source of the human infection might have been in Finland (see [14]).

However, our knowledge on prevalence epidemiology and pathogenesis of EBLVs remains partial and enigmatic. Clinically silent rabies infections have been described in several bat species worldwide [21-23]. Viral RNA has been detected in the saliva, blood and various organs of healthy bats captured in field colonies. The excretion of viral RNA in the saliva may persist and fluctuate over time [24]. Similarly, antiviral antibodies were also detected in healthy captured bats. On the other hand, most cases detected so far have been in diseased or dead animals, and experimental infection of bats usually leads to short excretion and fast death $[22,25]$. Nevertheless, the risk of rabies transmission to humans is real and raises important implications for bat management and bat specialists protection [26].

Herein, we present a compilation of the passive surveillance conducted so far and the results of a recent targeted survey in four bat species living in western Switzerland. In the targeted survey, we focused on M. daubentoni, M. myotis and E. serotinus, as members of these three species have been found to be infected with rabies virus in European countries, and on Nyctalus noctula, as this species migrates over long distances [27] and could potentially disseminate the disease over a large geographical range while infected. Myotis dasycneme is also a potential host for EBLV-2, but the species is not found in Switzerland.

\section{Materials and methods}

Sample collection

\section{(a) Passive surveillance}

Passive surveillance for EBLVs, based on dead and diseased animals with clinical suspicion, was initiated in Switzerland in 1966 by the Swiss Rabies Centre. Dead and freshly euthanized animals were submitted to the Swiss Rabies Centre by bat conservationists, museum curators, veterinarians or the general public.

\section{(b) Active surveillance}

Bats (M. daubentoni, M. myotis, E. serotinus and N. noctula) were captured in 2009 at 12 different locations around Lake Geneva and close to Lake Neuchâtel in the cantons of Vaud, Geneva and Fribourg, in Switzerland. Greater mouse-eared bats were captured either inside reproductive colonies $(n=40)$ or at the entrance of caves, noctule bats inside pre-hibernating colonies (nest boxes), serotine bats at the entrance of caves and Daubenton's bats while flying over rivers using mist nests or harptraps. The sex, reproductive status, age, body mass, forearm length and general body condition were recorded. Signs of poor health, such as poor condition of fur, state of emaciation, abnormal behaviour, parasitic load and excessively injured wings (rips, tears and punctures) were also recorded. A uniquely numbered bat ring (Museum of Natural History, Geneva, Switzerland) was fitted on each bat for future individual recognition. Capturing, handling, ringing and sampling of bats were done under the current laws of Switzerland (Authorization of Consumer and Veterinary Services of Canton of Vaud no. 2203, Switzerland).

Two oropharyngeal swabs (one dry, one wet) were taken from each bat to collect saliva in order to determine the presence of EBLV. The swabs were then immediately placed on dry ice $\left(4^{\circ} \mathrm{C}\right)$ and brought back to the laboratory. All swabs were stored at $-80^{\circ} \mathrm{C}$ until analysis.

Blood samples were taken with a $0.55 \times 25 \mathrm{~mm}$ needle (Romedic SA, Lausanne, Switzerland) from the uropatagial vein and collected in a Microvette CB300 capillary tube (Sarstedt, Nümbrecht, Germany) with EDTA. The volume of blood sampled varied between 5 and $100 \mu$ l. Haemostatic cotton (Flawa, Flawil, Switzerland) was then applied to the puncture site to prevent further bleeding and to facilitate healing. The bat was then kept for about $15 \mathrm{~min}$ 
after taking a blood sample to let it calm down. The health condition of each bat was assessed before its release. Blood samples were stored at $\sim 2^{\circ} \mathrm{C}$ in the field for a few hours. In the laboratory, samples were centrifuged at $1,400 \times g$ for $15 \mathrm{~min}$, and the plasma was stored at $-80^{\circ} \mathrm{C}$ until analysis.

Sample analysis

\section{(a) Detection of EBLV antigens}

The standard fluorescent antibody test (FAT) was performed on the brain tissues of all individuals from the passive surveillance programme using a previously described method [28].

\section{(b) Isolation of infectious virus}

Virus isolation was performed using a rabies tissue-culture infection test (RTCIT) with four consecutive passages in neuroblastoma cells (MNA 42/13, kindly provided by Dr. W. Müller, Tübingen, 1994) inoculated with $20 \%$ brain or saliva suspension, followed by immunofluorescence staining for rabies virus after each passage [29, 30].

\section{(c) Detection of EBLV RNA}

All saliva samples were analysed by RT-PCR to detect the presence of host and viral RNA. Five hundred microlitres of RNA Storage Solution (Ambion, Foster City, CA, USA) was added to either the wet or the dry frozen swab of each of the 237 bats sampled. The swabs were then thawed for $10 \mathrm{~min}$ at room temperature, vortexed vigorously for $1 \mathrm{~min}$, and then centrifuged at 5,000 rpm for $10 \mathrm{~min}$. RNA was extracted from $140 \mu \mathrm{l}$ of the supernatant using a QIAmp Viral RNA Kit (QIAgen, Germantown, MD, USA). To detect viral RNA, a reverse transcription PCR (RTPCR) was performed using a OneStep RT-PCR Kit (QIAgen, Germantown, MD, USA), following a protocol adapted from Vazquez-Moron et al. [31]. The primers GRAB1F and GRAB1R, designed by Vazquez-Moron et al. [31], bind to a conserved region of the nucleoprotein gene of the first seven recognized lyssavirus genotypes (260 bp). Nested PCR was performed using the primers GRAB2F and GRAB2R [31]. All amplifications were performed in a 2720 Thermal Cycler (Applied Biosystems, Foster City, CA, USA). PCR products were visualised under UV light after gel electrophoresis in $1.5 \%$ agarose.

The interpretation of PCR results assumed that each swab contained host material (host-derived RNA) from the oral cavity. In order to prevent false negative detection due to absence of host material, a second RT-PCR was conducted on each sample, using specific primers that bind to the mammalian glyceraldehyde-3-phosphate dehydrogenase
(GAPDH) gene according to Ravazzolo et al. [32]. The RTPCR reaction was conducted in a total volume of $50 \mu$ l, using a OneStep RT-PCR Kit (QIAgen, Germantown, MD, USA) as described above for the first round of nested PCR. PCR products were run on ethidium-bromide-stained polyacrylamide gels and visualized under UV light. GAPDHpositive samples showed a specific band at $125 \mathrm{bp}$.

Positive (CVS) and negative (RNA Storage Solution or $\mathrm{H}_{2} \mathrm{O}$ ) controls were added at each of the following steps: RNA extraction, RT-PCR, and nested PCR. When a saliva sample was found to be positive, the second corresponding saliva sample from that bat was also tested following the procedure described above.

\section{(d) Detection of EBLV antibodies}

A microtitre adaptation of RFFIT in 96-well microtitre tissue culture trays was performed essentially as described $[33,34]$. The samples were serially diluted from 1:25 to 1:625 in BHK-21 cell culture medium. A pool of human sera calibrated with the second International Standard Preparation for Rabies Immunoglobulins was used as a control standard [35]. CVS-11 (Challenge Virus Strain; [36]) or EBLV-2 virus was used as challenge virus. The virus-neutralizing antibody (VNA) titres were calculated according to Spearman and Kaerber $[37,38]$ by extrapolating the dilution of the sample that reduces the number of fluorescent microscopic fields to $50 \%$. International units (IU) were determined using a standard control $(9.0 \mathrm{IU} / \mathrm{ml})$.

\section{Phylogenetic reconstruction}

The 220-bp nucleotide sequences of the nucleoprotein gene obtained in this study were edited using MEGA v 4.0 [39], aligned using CLUSTAL 2.0.12 [40], visually inspected and manually corrected. Additional sequences were retrieved from GenBank (see Table 1).

Phylogenetic trees were constructed using two different methods: maximum likelihood (ML) and Bayesian analysis (BA). The model of DNA substitution was selected using jModeltest v 0.1.1 [41] and the minimum Akaike information criterion value. The HKY85 + G model best fitted the data. ML heuristic searches and bootstrap analyses (1,000 replicates) were performed using PHYML v 3.0 [42]. The BA was performed with MrBayes v 3.1.2 [43, 44]. Two independent runs were performed, each of them consisting of four parallel MCMC chains of five million generations, allowing a good convergence of the independent runs. After having visualised the parameters and controlled for a burn-in period using the software TRACER $\mathrm{v} 1.5$ [45], $10 \%$ of the trees were discarded as burn-in period. The remaining trees were used to construct a $50 \%$ major-consensus tree. 
Table 1 The site of collection, year of isolation, bat species and GenBank accession number for each EBLV strain used in the phylogenetic analyses

\begin{tabular}{clllll}
\hline Virus & Year of isolation & Locality & Country & Bat species & Accession no. \\
\hline EBLV-2 & & & & \\
70 & 2009 & Genthod (GE) & Switzerland & M.daubentoni & HM067110 \\
118 & 2002 & Geneva (GE) & Switzerland & M.daubentoni & HM067109 \\
RV1333 & 2002 & NA & United Kingdom & M.daubentoni & EF157977 \\
1392 & 1993 & Versoix (GE) & Switzerland & M.daubentoni & HM067108 \\
9375 & 1993 & Roden & The Netherlands & M.dasycneme & AY863404 \\
1814 & 1992 & Plaffeien (FR) & Switzerland & M.daubentoni & HM067107 \\
94112 & 1989 & Andijk & The Netherlands & M.dasycneme & AY863405 \\
9018 & 1987 & Wommels & The Netherlands & M.dasycneme & AY863403 \\
9007 & 1986 & Helsinki & Finland & Human & AY863406 \\
EBLV-1 & & & & & \\
102 & 2000 & Haute-Marne & France & E.serotinus & AY863399 \\
9477 & 1986 & Niedersachsen & Germany & E.serotinus & AY863357 \\
\hline
\end{tabular}

$N A$ information not available

a This study

\section{Results}

Passive surveillance and detection of EBLV antigens

A total of 837 bat brain specimens were analysed in FAT/ RTCIT between 1976 and 2009 (Table 2). Daubenton's bat was the only species found to be positive for lyssavirus infection. Three cases of EBLV-2b have been identified, one on August 24, 1992, in Plaffeien, canton of Fribourg, one on July 10, 1993, in Versoix, canton of Geneva, and one on September 2, 2002, in the city of Geneva, canton of Geneva. No bat infected with EBLV-1 has been recorded. The numbers of bats submitted annually varied from 0 to 5 from 1976 to 1985 to 11 to 90 since 1986 . Almost $50 \%$ of the submitted specimens were pipistrelles (Pipistrellus spp.). Notably, only 64 bats were $M$. daubentoni (7.6\%), and 21 were Eptesicus serotinus $(2.5 \%)$, which are the two main vectors of EBLVs. The surveillance intensity was regionally biased, with significantly higher numbers of submissions from large agglomerations than from the countryside, e.g. the area around the first Swiss case in the canton of Fribourg (Fig. 1). Overall, the area covered roughly corresponds to the most suitable habitats for bats in Switzerland, avoiding higher mountainous regions.

\section{Detection of EBLV antibodies}

A minimum volume of $5 \mu$ l of plasma is necessary to proceed with RFFIT. Thus, only 202 bats out of the 237 sampled were subjected to the analysis (124/148 M. daubentoni, 47/51 M. myotis, 17/23 E. serotinus and 14/15 N. noctula; Table 3 ). All samples were tested individually for antibody with CVS and/or EBLV-2b as challenge virus.

One hundred fifty specimens (109 M. daubentoni, $24 \mathrm{M}$. myotis, 10 E. serotinus and $7 \mathrm{~N}$. noctula) were tested in the
Table 2 The number of individuals and the percentage of each species $(\%)$ for all passive surveillance bat submissions from 1976 to 2009

\begin{tabular}{|c|c|c|c|}
\hline Species & $n$ submitted & $\%$ & Rabies positive \\
\hline Barbastella barbastellus & 3 & 0.4 & 0 \\
\hline Eptesicus nilssoni & 13 & 1.6 & 0 \\
\hline Eptesicus serotinus & 21 & 2.5 & 0 \\
\hline Hypsugo savii & 1 & 0.1 & 0 \\
\hline Myotis bechsteini & 5 & 0.6 & 0 \\
\hline Myotis blythii & 2 & 0.2 & 0 \\
\hline Myotis daubentoni & 64 & 7.6 & 3 \\
\hline Myotis myotis & 41 & 4.9 & 0 \\
\hline Myotis mystacinus & 45 & 5.4 & 0 \\
\hline Myotis nattereri & 4 & 0.5 & 0 \\
\hline Myotis sp. & 1 & 0.1 & 0 \\
\hline Nyctalus leisleri & 21 & 2.5 & 0 \\
\hline Nyctalus noctula & 68 & 8.1 & 0 \\
\hline Pipistrellus kuhli & 57 & 6.8 & 0 \\
\hline Pipistrellus nathusii & 112 & 13.4 & 0 \\
\hline Pipistrellus pipistrellus & 224 & 26.8 & 0 \\
\hline Pipistrellus pygmaeus & 11 & 1.3 & 0 \\
\hline Pipistrellus savii & 2 & 0.2 & 0 \\
\hline Plecotus auritus & 63 & 7.5 & 0 \\
\hline Plecotus austriacus & 5 & 0.6 & 0 \\
\hline Plecotus macrobullaris & 2 & 0.2 & 0 \\
\hline Plecotus sp. & 3 & 0.4 & 0 \\
\hline Pipistrellus sp. & 24 & 2.9 & 0 \\
\hline Vespertilio тигіnus & 31 & 3.7 & 0 \\
\hline Unspecified & 14 & 1.7 & \\
\hline Total & 837 & 100 & 3 \\
\hline
\end{tabular}

assay with CVS as the challenge virus, out of which 130 were tested at initial dilutions of 1:25, and 20 at 1:125.

One hundred sixty samples, including $94 \mathrm{M}$. daubentoni, 46 M. myotis, 11 E. serotinus and 9 N. noctula, were also 
Fig. 1 The distribution of records across Switzerland from passive bat rabies surveillance (1967-2009). The most frequently submitted species and the positive cases are indicated (including the two major host species E. serotinus and $M$. daubentoni). The coordinates of individual samples were shifted for clarity. 1 August 24, 1992,

M. daubentoni, Plaffeien, Fribourg, 2 July 10, 1993, M. daubentoni, Versoix, Geneva, 3 September 2, 2002, M. daubentoni, City of Geneva, Geneva

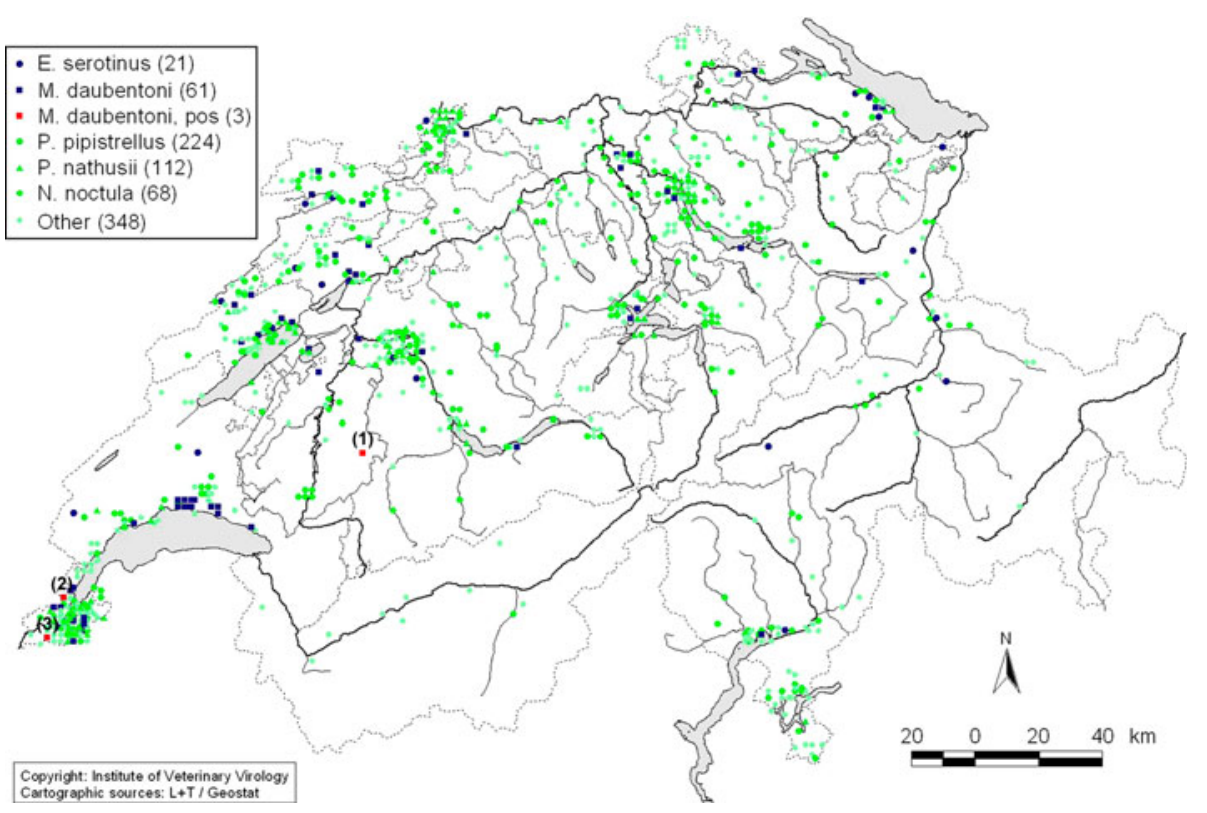

tested with EBLV-2b as the challenge virus (previously isolated from one of the three positive Swiss Daubenton's bats, ID 1392/93), out of which 126 were tested at an initial dilution of 1:25 and 35 at an initial dilution of 1:125.

Three bats, all Daubenton's bats from different sampling sites, were found to be seropositive. One specimen sampled in Baulmes, Vaud, was positive with CVS (titre 1:56) but could not be tested at the same initial dilution with EBLV$2 b$ (negative at 1:125 dilution). The other two seropositive bats were sampled in Dorigny, Vaud (titre 1:70), and in Genthod, Geneva (titre 1:314), and were found positive with EBLV-2b but not with CVS as challenge virus. Following previous suggestions, we used a reciprocal titre of $\geq 27$ as the positive threshold [46].

\section{Detection of EBLV RNA}

A total of 237 bats, including $148 M$. daubentoni, 51 M. myotis, 23 E. serotinus and $15 \mathrm{~N}$. noctula, were analysed. Host GAPDH was detected in all of the swabs analysed, indicating that material originating from the sampled bat was present on the swab. No difference in the

Table 3 The number of individuals sampled around Lake Geneva and close to Lake Neuchâtel, tested serologically (CVS/EBLVs) and by RT-PCR for rabies, per site and per species of bats

\begin{tabular}{llcll}
\hline Species & $n$ sites & $n$ sampled & $n$ RFITT/+ & $n$ RT-PCR/+ \\
\hline M. daubentoni & 9 & 148 & $124 / 3$ & $148 / 1$ \\
M. myotis & 4 & 51 & $47 / 0$ & $51 / 0$ \\
N. noctula & 2 & 15 & $14 / 0$ & $15 / 0$ \\
E. serotinus & 1 & 23 & $17 / 0$ & $23 / 0$ \\
Total & & 237 & $202 / 3$ & $237 / 1$ \\
\hline
\end{tabular}

ability to detect RNA in the wet or dry swabs was observed. Both methods are therefore suitable to swab bats. Of the 237 bats sampled, only one Daubenton's bat $(0.4 \%)$ was found positive for EBLV-2b RNA by the nested PCR approach, using both wet and dry swabs. Virus isolation over four passages using RTCIT was negative with both swabs. This bat was an adult female caught in Genthod in the canton of Geneva. It was found to host nine parasitic wing mites (Spinturnix andegavinus) and did not show any signs of poor health or unusual behaviour.

\section{Phylogenetic reconstruction}

The two phylogenetic methods used, ML and BA, resulted in similar tree topologies. The resulting phylogeny obtained by BA analysis is presented in Fig. 2. The sequence of the Daubenton's bat sample (Genthod, canton of Geneva) that was found to be positive in RT-PCR (DEE70.SWI) grouped with the other three EBLV-2b sequences identified previously in Swiss Daubenton's bats, particularly with the one that was found in the city of Geneva in 2002 (118.SWI). The bootstrap support for the subdivision of EBLV-2 in the lineages EBLV-2a and EBLV-2b as suggested before [24] is reasonable (0.91 in BA) but not overwhelming.

\section{Discussion}

The present study confirms the presence of EBLV-2 and extends our knowledge about its epidemiology in the Swiss bat population. The pattern of passive surveillance showed clear drawbacks, both with respect to spatial distribution 


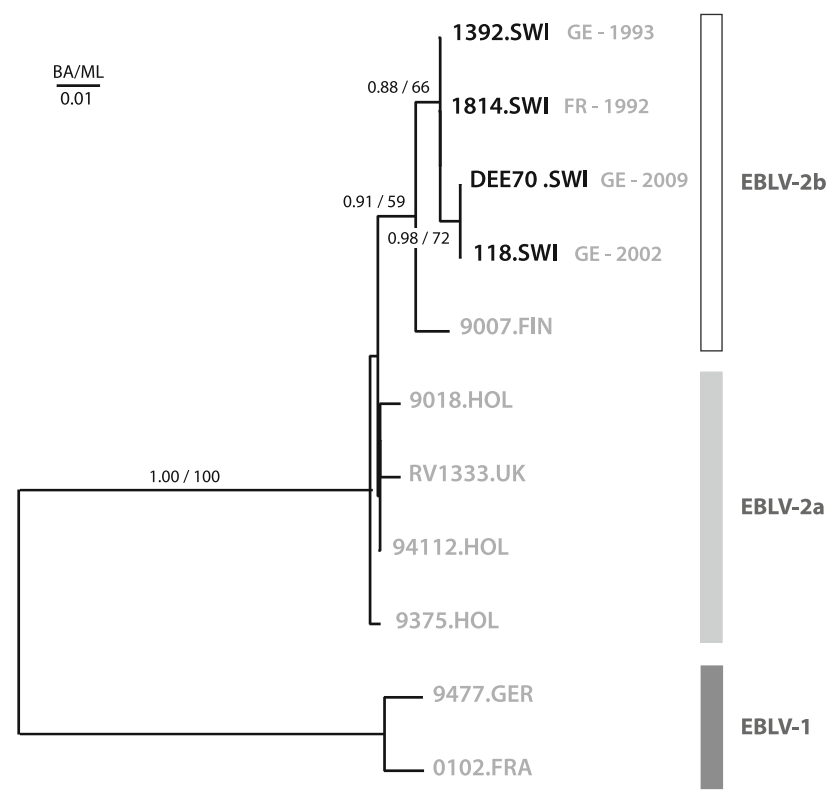

Fig. 2 Consensus Bayesian phylogenetic tree (50\% majority consensus) and branch length for partial nucleoprotein gene sequences from GenBank, depicting the relationships of the Swiss isolates to other isolates. The tree is rooted with two $E B L V-1$ samples. The results are based on two runs of $5 \times 10^{6}$ generations, each with 4 chains

and the species representation of the main vectors $E$. serotinus and $M$. daubentoni. During the passive surveillance, three $M$. daubentoni were found to be positive for EBLV-2, in 1992, 1993 and 2002. During the 4-month targeted surveillance programme, seropositive healthy Daubenton's bats and a PCR-positive saliva of another healthy Daubenton's bat were found. This RT-PCR-positive bat was captured in Genthod, close to Versoix, where the second case of EBLV in Swiss bats was detected in 1993. This sequence is closely related to the corresponding sequences of the other three cases of EBLV-2 diagnosed in Switzerland. Recently, EBVL-2 has also been detected in a Daubenton's bat in Germany [18].

Both the detection of neutralizing antibodies in blood samples, indicating past exposure to EBLV, and the detection of viral RNA in oropharyngeal swabs suggest recent active circulation of EBLV in Swiss Daubenton's bats, confirming the potential for disease spread. Not a single bat from the three other species sampled (Serotine bat, Noctule bat and Great mouse-eared bat) gave a positive reaction by serology or RT-PCR. Out of the three seropositive Daubenton's bats, one was found positive with CVS as challenge virus, probably due to serological crossreactivity with EBLVs. The other two samples were positive with EBLV-2b but not with CVS, indicating higher sensitivity of the neutralization test when using EBLV as the challenge virus. The seroprevalence over the different Daubenton's bats was $2.4 \%$ (3 of 24 bats tested), whereas the prevalence estimated by RT-PCR was lower, with $0.7 \%$ of individuals reacting positively (1/148). The low prevalence found in this work seems to be in accordance with the north-to-south gradient in the frequency of EBLVs detected in Western Europe using classical techniques for viral detection [47]. In Scotland, a seroprevalence of 0.05-3.8\% has been detected while screening $M$. daubentoni [48]. In a recent active survey in England, a seroprevalence of 1.0$4.1 \%$ was found, while no virus was detected using both RT-PCR and RTCIT in 363 M. daubentoni bats sampled [46].

EBLV-1 is the most common virus found across northern and central Europe as far east as Russia, and in western European countries as far south as Spain (reviewed in ref. [49]). Germany and the Netherlands are the only countries in which both EBLV-1 and EBLV-2 have been detected. EBLV-1 has a specific association with the serotine bat as the main vector, but it has also been reported in greater mouse-eared bats in Spain $[50,51]$ and in noctule bats in Germany [52]. Although serotine bats, noctule bats and greater mouse-eared bats are frequently found across Switzerland ([53] and Centre Suisse de Cartographie de la Faune, Neuchâtel), few samples have been analysed (Table 2) and none were found positive in the present study. In view of regular cases encountered in serotine bats both in France and Germany [13, 54], this infection may have been missed in both passive and active surveillance so far due to the limited number of individuals tested and the biased distribution of sampling.

Appreciation of the potential for epidemiological spread and disease risk requires an understanding of host dispersal. Seasonal movements of bats between summer and winter roosts over hundreds of kilometres may provide opportunities for disease spread. A noctule bat ringed in Lausanne, Switzerland, was caught $670 \mathrm{~km}$ farther north, near Leipzig, Germany (P. Christe, O. Glaizot, and D. Brockmann, personal communication), and movements up to $1,500 \mathrm{~km}$ have been recorded for this species [55]. A recent genetic study revealed a relative genetic uniformity of UK and European continental Daubenton's bat populations, implying that there is no migration barrier to EBLV-2 between regions [56]. Movement of bats over long distances is therefore common and important with respect to the epidemiology of EBLV, indicating a high potential for spread of disease.

\section{Conclusion}

Overall, the results of this study suggest that the publichealth risk of infection with EBLV is moderate to low in Switzerland. Nonetheless, the practice of considering rabies in both humans and animals with a course of progressive encephalitis, also in the absence of a known 
history of exposure, must be maintained and ensured. The risk of cross-species transmission to both humans and animals is highest in clinically diseased, disoriented animals with bizarre behaviour. EBLV-1 has not been detected in any of the bats sampled, and EBLV-2 seems to be present only at a very low prevalence. However, with the present confirmation of EBLV-2 infection in Daubenton's bats, and considering the biased sampling, the epidemic picture of EBLV in Switzerland remains incomplete. Therefore, both active and passive surveillance must be intensified in order to assess more appropriately the potential risk to public health.

Acknowledgements We thank the following persons who helped with the field sampling: Simone Giavi, Nadia Bruyndonckx, Ludovic Dutoit, Sébastien Pichard, Cyril Schönbächler, Pascal Roduit, Antoine Gander and Georges Gilliéron. Dr. A. Kappeler and Dr. U. Breitenmoser are greatly acknowledged for establishment and maintenance of passive bat rabies surveillance. We also thank Pascal Moeschler and the Centre de coordination ouest pour l'étude et la protection des chauves-souris for support and funding. Jonathan Yearsley gave advice for the English writing. We thank two anonymous reviewers for comments that improved the quality of this manuscript. This project was supported by a grant from the Fondation Bruno Galli-Valerio.

\section{References}

1. Wong S, Lau S, Woo P, Yuen KY (2007) Bats as a continuing source of emerging infections in humans. Rev Med Virol 17:67-91

2. Calisher CH, Childs JE, Field HE, Holmes KV, Schountz T (2006) Bats: important reservoir hosts of emerging viruses. Clin Microbiol Rev 19(3):531-545. doi:10.1128/cmr.00017-06

3. Brückner G (2009) Rabies: the role of the world organisation for animal health in mobilising global control. Vaccine 27(51): 7139-7140

4. Johnson N, Vos A, Freuling C, Tordo N, Fooks AR, Müller T (2010) Human rabies due to lyssavirus infection of bat origin. Vet Microbiol 138(3):305-312

5. Bourhy H, Kissi B, Tordo N (1993) Molecular diversity of the lyssavirus genus. Virology 194(1):70-81

6. Kuzmin IV, Wu XF, Tordo N, Rupprecht CE (2008) Complete genomes of Aravan, Khujand, Irkut and West Caucasian bat viruses, with special attention to the polymerase gene and non-coding regions. Virus Res 136(1-2):81-90. doi:10.1016/j. virusres.2008.04.021

7. ICTV (2009) Ictv official taxonomy: updates since the 8th report, 2009. Vertebrate, http://talk.Ictvonline.Org/media/p/1208.Aspx. Accessed 14 Oct 2009

8. Kuzmin IV, Mayer AE, Niezgoda M, Markotter W, Agvvanda B, Breiman RF, Rupprecht CE (2010) Shimoni bat virus, a new representative of the lyssavirus genus. Virus Res 149(2):197-210. doi:10.1016/j.virusres.2010.01.018

9. Anonymous (2004) World health organization: Expert consultation on rabies. World Health Organ Tech Rep Ser 931:1-121

10. Mohr W (1957) Die tollwut. Med Klinik 52:1057-1060

11. Rabies Bulletin Europe (2008) Bats-special protection and rabies in Europe, available from http://www.who-rabies-bulletin.org/

12. Van der Poel WHM, Van der Heide R, Verstraten E, Takumi K, Lina PHC, Kramps JA (2005) European bat lyssaviruses, The Netherlands. Emerg Infect Dis 11(12):1854-1859
13. Muller T, Johnson N, Freuling CM, Fooks AR, Selhorst T, Vos A (2007) Epidemiology of bat rabies in Germany. Arch Virol 152(2):273-288. doi:10.1007/s00705-006-0853-5

14. Jakava-Viljanen M, Lilley T, Kyheroinen E-M, Huovilainen A (2010) First encounter of european bat lyssavirus type 2 (eblv-2) in a bat in Finland. Epidemiol Infect 3:1-5

15. Zanoni R (2002) Rabies in individual countries: Switzerland. Rabies Bulletin Europe 26(3):7

16. Harris SL, Mansfield K, Marston DA, Johnson N, Pajamo K, O'Brien N, Black C, McElhinney LM, Fooks AR (2007) Isolation of European bat lyssavirus type 2 from a Daubenton's bat (Myotis daubentonii) in Shropshire. Vet Rec 161(11):384-386

17. Horton DL, Voller K, Haxton B, Johnson N, Leech S, Goddard T, Wilson C, McElhinney LM, Fooks AR (2009) European bat lyssavirus type 2 in a Daubenton's bat in Scotland. Vet Rec 165(13):383-384

18. Freuling C, Grossmann E, Conraths FJ, Schameitat A, Kliemt J, Auer E, Greiser-Wilke I, Muller T (2008) First isolation of EBLV-2 in Germany. Vet Microbiol 131(1-2):26-34. doi: 10.1016/j.vetmic.2008.02.028

19. Lumio J, Hillbom M, Roine R, Ketonen L, Haltia M, Valle M, Neuvonen E, Lahdevirta J (1986) Human rabies of bat origin in Europe. Lancet 1(8477):378

20. Hagner N, Ek-Kommonen C, Lokki J, Neuvonen E, Stjernberg T, Valle M, Veijalainen P (1989) No bat rabies found in Finland 1986. Eur Bat Res 1987:631-635

21. Fooks AR, Brookes SM, Johnson N, McElhinney LM, Hutson AM (2003) European bat lyssaviruses: an emerging zoonosis. Epidemiol Infect 131(3):1029-1039

22. Freuling C, Vos A, Johnson N, Kaipf I, Denzinger A, Neubert L, Mansfield K, Hicks D, Nunez A, Tordo N, Rupprecht CE, Fooks AR, Muller T (2009) Experimental infection of serotine bats (Eptesicus serotinus) with European bat lyssavirus type 1a. J Gen Virol 90:2493-2502. doi:10.1099/vir.0.011510-0

23. Vos A, Kaipf I, Denzinger A, Fooks AR, Johnson N, Müller T (2007) European bat lyssaviruses: an ecological enigma. Acta Chiropt 9(1):283-296

24. Amengual B, Whitby JE, King A, Cobo JS, Bourhy H (1997) Evolution of European bat lyssaviruses. J Gen Virol 78: 2319-2328

25. Johnson N, Vos A, Neubert L, Freuling C, Mansfield KL, Kaipf I, Denzinger A, Hicks D, Nunez A, Franka R, Rupprecht CE, Muller T, Fooks AR (2008) Experimental study of European bat lyssavirus type- 2 infection in Daubenton's bats (Myotis daubentonii). J Gen Virol 89:2662-2672. doi:10.1099/vir.0.2008/ 003889-0

26. Kirkbride H, Brown K, Morgan D, Larkin L (2008) Rabies risk from contact with bats. Vet Rec 163(16):491

27. Petit E, Mayer F (1999) Male dispersal in the noctule bat (Nyctalus noctula): where are the limits? Proc Biol Sci 266(1430): $1717-1722$

28. Dean DJ, Abelseth MK (1973) The fluorescent antibody test. In: Kaplan MM (ed) Laboratory techniques in rabies, 3rd edn. World Health Organization, pp 73-83

29. Gerhardt A (1995) Teilvalidierung einer zellkulturmethode als alternative zum tierversuch für den nachweis von tollwutvirus aus hirnmaterial. Universität Bern, Bern

30. Rudd RJ, Trimarchi CV (1987) Comparison of sensitivity of BHK-21 and murine neuroblastoma cells in the isolation of a street strain rabies virus. J Clin Microbiol 25:1456-1458

31. Vazquez-Moron S, Avellon A, Echevarria J (2006) RT-PCR for detection of all seven genotypes of lyssavirus genus. J Virol Methods 135:261-287

32. Ravazzolo AP, Nenci C, Vogt HR, Waldvogel A, Obexer-Ruff G, Peterhans E, Bertoni G (2006) Viral load, organ distribution, histopathological lesions, and cytokine mRNA expression in 
goats infected with a molecular clone of the caprine arthritis encephalitis virus. Virology 350:116-127

33. Smith JS, Yager PA, Baer GM (1973) A rapid reproducible test for determining rabies neutralizing antibody. Bull WHO 48:535-541

34. Zalan E, Wilson C, Pukitis D (1979) A microtest for the quantitation of rabies virus neutralizing antibodies. J Biol Stand 7:213-220

35. Lyng J (1994) Calibration of a replacement preparation for the international standard for rabies immunoglobulin. Biologicals 22:249-255

36. Cliquet F, Aubert M, Sagne L (1998) Development of a fluorescent antibody virus neutralisation test (favn test) for the quantitation of rabies-neutralising antibody. J Virol Methods 212:79-87

37. Spearman C (1908) The method of "right or wrong cases" (constant stimuli) without Gauss's formulae. Br J Psychol 2:227-242

38. Kaerber G (1931) Beitrag zur kollektiven behandlung pharmakologischer reihenversuche. Arch Exp Pathol Pharmakol 162:480-487

39. Tamura K, Dudley J, Nei M, Kumar S (2007) Mega4: molecular evolutionary genetics analysis (mega) software version 4.0. Mol Biol Evol 24:1596-1599

40. Thompson JD, Gibson TJ, Plewniak F, Jeanmougin F, Higgins DG (1997) The clustal_x windows interface: flexible strategies for multiple sequence alignment aided by quality analysis tools. Nucleic Acids Res 25(24):4876-4882

41. Posada D (2008) Jmodeltest: phylogenetic model averaging. Mol Biol Evol 25:1253-1256

42. Guindon S, Gascuel O (2003) A simple, fast, and accurate algorithm to estimate large phylogenies by maximum likelihood. Syst Biol 52:692-704

43. Ronquist F, Huelsenbeck JP (2003) Mrbayes 3: Bayesian phylogenetic inference under mixed models. Bioinformatics 19(12): $1572-1574$

44. Huelsenbeck JP, Ronquist F (2001) Mrbayes: Bayesian inference of phylogenetic trees. Bioinformatics 17(8):754-755

45. Rambaut A, Drummond A (2007) Tracer v1.4, available from http://beast.Bio.Ed.Ac.Uk/tracer

46. Brookes SM, Aegerter JN, Smith GC, Healy DM, Jolliffe TA, Swift SM, Mackie IJ, Pritchard S, Racey PA, Moore NP, Fooks
AR (2005) European bat lyssavirus in Scottish bats. Emerg Infect Dis 11(4):572-578

47. Müller WW (1996) Review of reported rabies case data in Europe to the WHO collaborating centre Tübingen from 1977 to 1996. Rabies Bull Eur 20(4):11-18

48. Harris SL, Aegerter JN, Brookes SM, McElhinney LM, Jones G, Smith GC, Fooks AR (2009) Targeted surveillance for European bat lyssaviruses in English bats. J Wildl Dis 45(4):1030-1041

49. Davis PL, Holmes EC, Larrous F, Van der Poel WHM, Tjornehoj K, Alonso WJ, Bourhy H (2005) Phylogeography, population dynamics, and molecular evolution of European bat lyssaviruses. J Virol 79(16):10487-10497. doi:10.1128/jvi.79.16.10487-10497. 2005

50. Amengual B, Bourhy H, Lopez-Roig M, Serra-Cobo J (2007) Temporal dynamics of European bat lyssavirus type 1 and survival of Myotis myotis bats in natural colonies. PloS One 2(6):e566

51. Serra-Cobo J, Amengual B, Abellan C, Bourhy H (2002) European bat lyssavirus infection in Spanish bat populations. Emerg Infect Dis 8(4):413-420

52. Müller T, Cox J, Peter W, Schafer R, Johnson N, McElhinney LM, Geue JL, Tjornehoj K (2004) Spill-over of European bat lyssavirus type 1 into a stone marten (Martes foina) in Germany. J Vet Med B Infect Dis Vet Public Health 51(2):49-54

53. Hausser J (1995) Mammifères de la suisse: Répartition biologie ecologie. Birkhäuser Verlag, Bâle-Boston-Berlin

54. Picard-Meyer E, Barrat J, Wasniewski M, Wandeler A, NadinDavis S, Lowings JP, Fooks AR, McElhinney L, Bruyere V, Cliquet F (2004) Epidemiology of rabid bats in France, 1989 to 2002. Vet Rec 155(24):774-777

55. Hutterer R, Ivanova T, Meyer-Cords C, Rodrigues L (2005) Bat migrations in Europe. A review of banding data and literature, vol Heft 28. Natuschutz und biologishe vielfalt. Federal Agency for Nature Conservation, Bonn

56. Atterby H, Aegerter JN, Smith GC, Conyers CM, Allnutt TR, Ruedi M, MacNicoll AD (2010) Population genetic structure of the Daubenton's bat (Myotis daubentonii) in Western Europe and the associated occurrence of rabies. Eur J Wildl Res 56(1):67-81. doi:10.1007/s10344-009-0292-1 